\title{
Lipid-lipid interactions of Escherichia coli mimetic inner membrane at human physiological temperature
}

\author{
Javier Hoyo, Juan Torrent-Burgués and Tzanko Tzanov \\ Group of Molecular and Industrial Biotechnology, Department of Chemical Engineering, Universitat Politecnica de Catalunya, \\ Terrasa, Spain
}

\begin{abstract}
The current strategies to eradicate bacteria require that the antimicrobial agent either penetrate or disrupt the bacterial membrane. In Escherichia coli (E.coli) as a model of Gram-negative strains, the antimicrobials have to cross two barriers - the outer and the inner membrane being the latter composed by 77\% phosphatidylethanolamine (PE), 13\% phosphatidylglycerol (PG) and $\sim 10 \%$ cardiolipin (CL) lipids. Each one of these lipid families shares the same headgroup, but contains acyl chains with varying length and degree of unsaturation. Bacteria adapt their membrane lipid composition and metabolism in response to environmental signals, such as the temperature, resulting in different interactions with exogenous molecules, e.g. antibacterial agents. Herein, bacterial model membranes are prepared to evaluate the lipid-lipid interactions in Langmuir monolayers of binary mixtures at several molar ratios of PE and PG or CL at human physiological temperature $\left(37^{\circ} \mathrm{C}\right)$. Both PE:PG and PE:CL monolayers were stable at $37^{\circ} \mathrm{C}$ and presented higher molecular areas (> $20 \AA^{2} /$ molecule) than at $23^{\circ} \mathrm{C}$. However, these lipid mixtures presented liquid-expanded state and rigidity (inverse of the compressibility modulus $\sim 90 \mathrm{mN} / \mathrm{m}$ ) slightly lower than at $23^{\circ} \mathrm{C}$. Such athermalicity at biologically relevant temperatures may favour the preservation of the biological functions of E.coli.
\end{abstract}

Key words: Phosphatidylethanolamine - Phosphatidylglycerol - Cardiolipin — Lipid-lipid interactions - Bacterial mimetic membranes - Physiological temperature

\begin{abstract}
Abbreviations: CL, cardiolipin; DPPG, dipalmitoylphosphatidylglycerol; E.coli, Escherichia coli; LB, Langmuir-Blodgett; LC, liquid condensed; LE, liquid expanded; PE, phosphatidylethanolamine; PG, phosphatidylglycerol; PLE, polar lipid extract; POPE, palmitoyloleoylphosphatidylethanolamine; POPG, palmitoyloleoylphosphatidylglycerol.
\end{abstract}

\section{Introduction}

Most recent strategies to eradicate bacteria, rely on disruption of the bacterial membrane with nano-formulated antimicrobial agents that ultimately causes cell death with less probability for resistance development (Ivanova et al. 2017; Ferreres et al. 2018; Hoyo et al. 2019a). However, the majority of clinically relevant antibiotics need to cross the membrane of Gram-negative bacteria such as Escherichia

Correspondence to: Javier Hoyo, Grup de Biotecnologia Molecular i Industrial, Departament d'Enginyeria Química, Universitat Politècnica de Catalunya, Rambla Sant Nebridi 22, 08222, Terrasa, Spain E-mail: javier.hoyo@upc.edu coli (E.coli) in order to exert their antibacterial effect. The outer membrane of E.coli is mainly composed of lipopolysaccharides, while the inner membrane contains mainly lipids ( 77\% phosphatidylethanolamine (PE), 13\% phosphatidylglycerol (PG), and $~ 10 \%$ cardiolipin (CL)) and proteins (Shokri and Larsson 2004; Yeagle 2016). Langmuir and Langmuir Blodgett (LB) films have been used to study in vitro the antibacterial mechanism of new agents (Fernandes et al. 2017; Ivanova et al. 2018). Simple and reproducible mammalian (Nichols-Smith et al. 2004; Domènech et al. 2006), thylakoid (Hoyo et al. 2012, 2015, 2016a, 2016b), and bacterial (Gidalevitz et al. 2003; Clausell et al. 2007; LópezMontero et al. 2008; López-Montero et al. 2010; Michel et al. 2015, 2017) membrane models have been prepared using 
these techniques for studying the interactions of exogenous molecules, including antibacterial agents, with bacterial membranes. Previous works reported the application of inner bacterial membrane models composed of a single lipid, e.g. dipalmitoylphosphatidylglycerol (DPPG) (Gidalevitz et al. 2003) and palmitoyloleoylphosphatidylglycerol (POPG) (Gidalevitz et al. 2003; Clausell et al. 2007), while the outer bacterial membrane was mimicked by lipopolysaccharides (LPS) (Clausell et al. 2007). The validity of these models was compromised by the use of only one lipid and the absence of PE, the major lipid present in bacterial inner membranes (Yeagle 2016). Michel et al. (2015) mimicked separately the outer and inner leaflets by the use of LPS and a ternary mixture of monounsaturated bacterial phospholipids. Furthermore, the same authors prepared a similar model with a unique structure combining the LB and Langmuir Schaefer techniques (Michel et al. 2017). Both models lacked the use of natural lipid constituents of the bacterial membranes. López-Montero et al. $(2008,2010)$ solved this drawback using an E.coli polar lipid extract (PLE) comprised of a myriad of lipid structures sharing the same headgroup. Recently, we prepared biomimetic membrane models using also a myriad of lipid structures to evaluate the lipid-lipid interactions in binary mixtures composed of $\mathrm{PE}$ and $\mathrm{PG}$ or $\mathrm{CL}$ at $23^{\circ} \mathrm{C}$. The models revealed that all tested ratios of lipids were in fluid state (liquid expanded, LE) and minor changes in terms of membrane rigidity were observed among the PE content in the mixture (Hoyo et al. 2019b).

Bacteria regulate their metabolism, membrane lipid composition and the degree of unsaturation of their hydrocarbon chains as a response to environmental signals
(Larsson and Törnkvist 1996; Shokri and Larsson 2004). Several biomimetic membrane studies have shown relevant differences in the lipid-lipid (Suárez-Germà et al. 2011) or lipid-polymer (Krajewska et al. 2013a, 2013b) interactions upon increasing the temperature. Therefore, studying the role of temperature in bacterial mimetic inner membranes could anticipate the interactions between novel antibacterial agents and the membrane. Herein, our previous study of PE:PG and PE:CL monolayers at $23^{\circ} \mathrm{C}$ (Hoyo et al. 2019b) is reproduced at human physiological temperature of $37^{\circ} \mathrm{C}$. The surface pressure-area isotherms of Langmuir films describe the physical states, rigidity and thermodynamic properties of the monolayers at the air/water interface (Fig. 1). The use of natural E.coli lipid extracts of the myriad of structures corresponding to each lipid, and the study of several binary mixtures of lipids, including the biologically relevant one, allows for a reliable evaluation of the lipid-lipid interactions in E.coli mimetic membranes to serve potentially as a model for validation of novel antibacterial agents.

\section{Materials and Methods}

\section{Materials}

Avanti Polar Lipids, Inc. provided PE (\# 840027), PG (\#841188) and CL (\#841199) extracted from E.coli. Each lipid represents a myriad of structures that share the same headgroup, but differ in their degree and position of unsaturation. $\mathrm{CHCl}_{3}$ and phosphate buffer solution (PBS) tablets were provided by Sigma-Aldrich (Spain). Ultrapure MilliQ
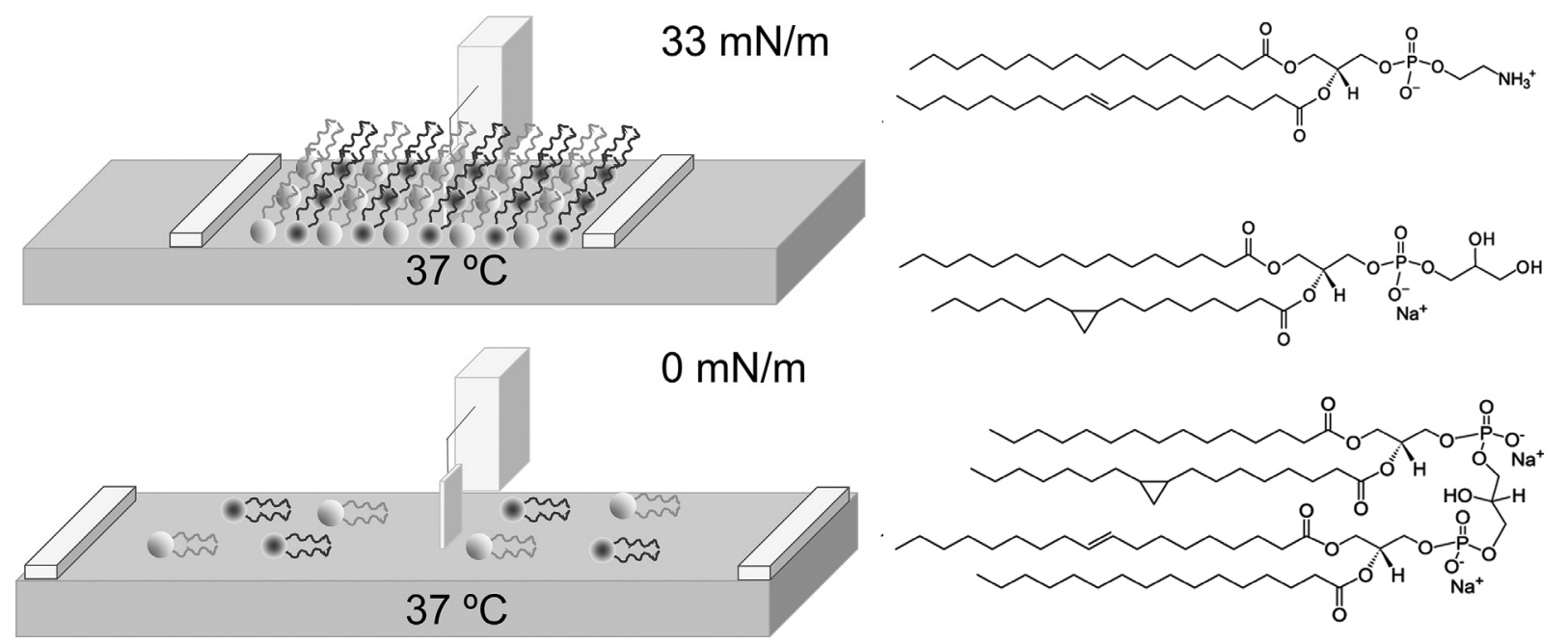

Figure 1. Scheme of a Langmuir monolayer formation and representative chemical structure of the myriad of lipid structures that shares the same headgroup: phosphatidylethanolamine (PE), phosphatidylglycerol (PG) and cardiolipin (CL) in lipid extracts from E.coli. (For more information, see section Materials and Methods). 


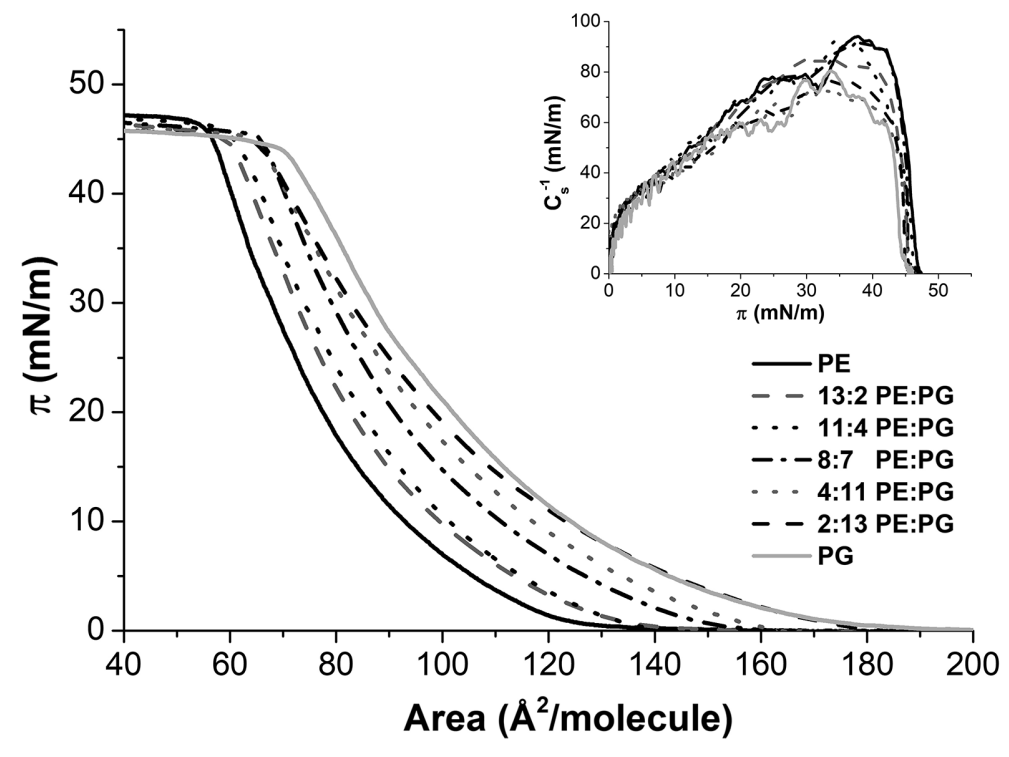

Figure 2. Surface pressure-area $(\pi-A)$ isotherms for phosphatidylethanolamine (PE), phosphatidylglycerol (PG) and PE:PG mixtures on PBS subphase at $37^{\circ} \mathrm{C}$. Inset: Inverse of the compressibility modulus $\left(\mathrm{C}_{\mathrm{s}}{ }^{-1}\right) v s$. surface pressure corresponding to the described $\pi$-A isotherms. water with a resistivity of $18.2 \mathrm{M} \Omega / \mathrm{cm}$ was used in cleaning procedures and for PBS at $\mathrm{pH} 7.4$ preparation.

\section{Surface pressure - area isotherms}

PE, PG, and CL solutions in $\mathrm{CHCl}_{3}(0.5 \mathrm{mg} / \mathrm{ml})$ and the corresponding mixtures at different molar ratios were prepared by mixing each stock solution and were stored at $-20^{\circ} \mathrm{C}$ until used. Surface pressure-area $(\pi-\mathrm{A})$ isotherms were performed in a Langmuir trough equipped with two mobile barriers (KSV NIMA, model KN2002, Finland) with a total area of $273 \mathrm{~cm}^{2}$ mounted on an antivibration table and housed in an insulation box at $37 \pm 1^{\circ} \mathrm{C}$. The temperature was maintained by connecting a thermostatic water bath to the inner circuit of the Langmuir trough and placing a temperature probe in the subphase. The Langmuir trough was cleaned with $\mathrm{CHCl}_{3}$ and water. After subphase addition, the surface was further cleaned by suctioning. Immediately, $25 \mu \mathrm{l}$ of the lipid or lipid mixture solution was added dropwise into the trough, and after $10 \mathrm{~min}$ evaporation of $\mathrm{CHCl}_{3}$, the barriers were compressed at $25 \mathrm{~cm}^{2} / \mathrm{min}$. $\pi$-A isotherms were performed by triplicate.

\section{Data analysis}

\section{Physical states}

The inverse of the compressibility modulus $\mathrm{C}_{\mathrm{s}}^{-1}$ was obtained from the $\pi$-A isotherms calculated according to Equation 1, where $\mathrm{A}$ is the mean area per molecule $\left(\AA^{2} /\right.$ molecule), $\pi$ the surface pressure $(\mathrm{mN} / \mathrm{m})$ and $\mathrm{T}$ the absolute temperature $(\mathrm{K})$.
$C_{S}^{-1}=-A\left(\frac{d \pi}{d A}\right)_{T}$

\section{Thermodynamic study}

The mixing energy $\left(\Delta \mathrm{G}_{\mathrm{mix}}\right)$ of a mixture is obtained from the following equation in which $A^{E}$ represents the excess area, $A_{1}$ and $A_{2}$ the area per molecule for the individual components, $A_{12}$ the mean area per molecule for the mixture, $x_{1}$ and $x_{2}$ the molar fraction for each component, $G^{E}$ the excess free energy of mixing, $N_{A}$ the Avogadro's number, R the gas constant and $\mathrm{T}$ the absolute temperature.

$$
\begin{aligned}
& A^{E}=A_{12}-\left(x_{1} A_{1}+x_{2} A_{2}\right) \\
& G^{E}=N_{A} \int_{0}^{\pi} A^{E} d \pi \\
& \Delta G_{\text {mix }}=\Delta G_{i d}+G^{E} \\
& \Delta G_{i d}=R T\left(x_{1} \ln x_{1}+x_{2} \ln x_{2}\right)
\end{aligned}
$$

\section{Results}

\section{$\pi$ - $A$ isotherms, physical states and mixing behaviour of $P E: P G$ system}

The lift-off area for PE and PG at $37^{\circ} \mathrm{C}$ was observed at 135 and $185 \AA^{2} /$ molecule and the collapse at $\pi=46$ and $45 \mathrm{mN} / \mathrm{m}$, respectively (Fig. 2). The isotherms were continuous and the $\mathrm{C}_{\mathrm{s}}^{-1}$ curves reached their maximum $\left(\mathrm{C}_{\mathrm{s}}{ }^{-1}\right.$ max $)$ at $\approx 94$ and $80 \mathrm{mN} / \mathrm{m}$ (inset of Fig. 2) for PE and PG, respectively, confirming the LE (Vitovič et al. 2006) physical state of the system. The studied PE:PG mixtures show similar 

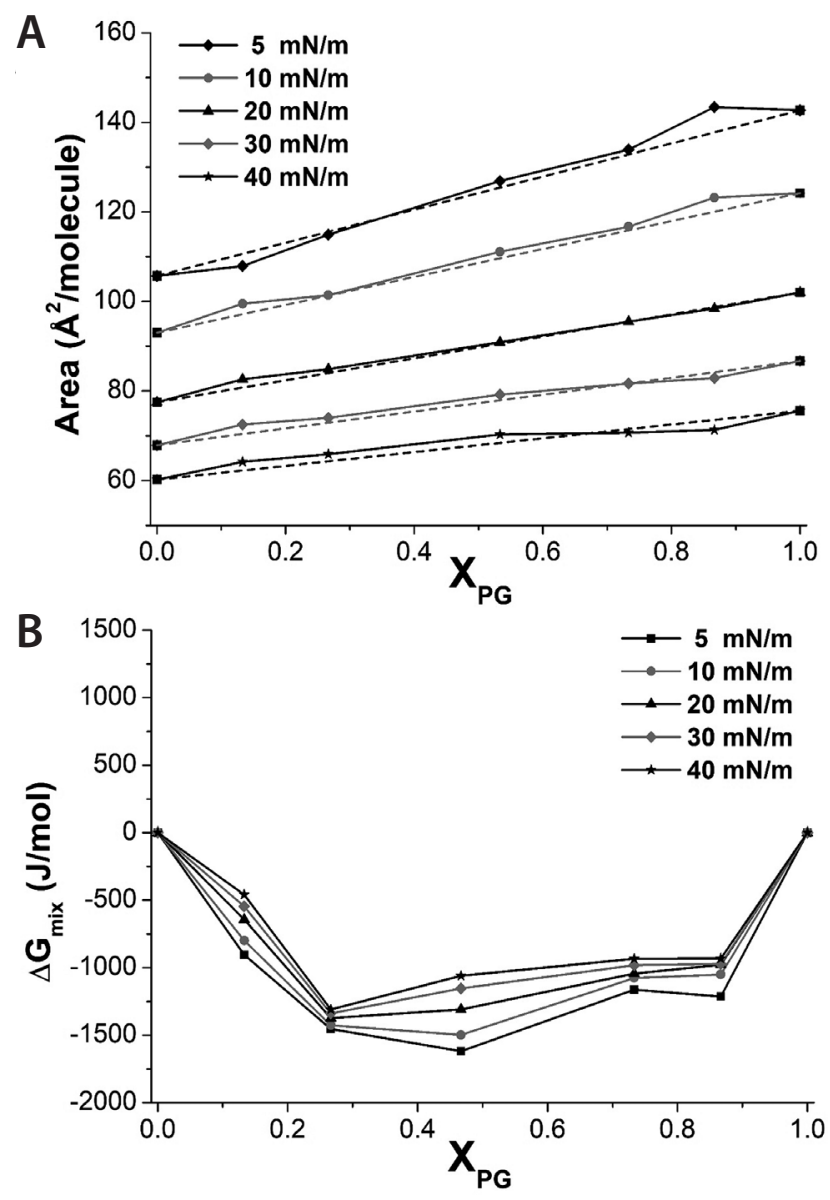

Figure 3. Mean area per molecule $v$ s. molar fraction $\left(\mathrm{X}_{\mathrm{PG}} ; \mathbf{A}\right)$ and mixing energy $\left(\Delta \mathrm{G}_{\text {mix }}\right) v s$. molar fraction (B) at several surface pressures for the $\mathrm{PE}: \mathrm{PG}$ system at $37^{\circ} \mathrm{C}$. Discontinuous straight line represents the ideal behaviour for each surface pressure. isotherms and $\mathrm{C}_{\mathrm{s}}^{-1}$ curves, mainly differing in the lift-off area that was higher upon increasing the amount of PG in the mixture. PE and PG showed similar size and shape. However, the PG headgroup is slightly larger than the headgroup of $\mathrm{PE}$, explaining the differences observed in the lift-off area. The average molecular area (Fig. 3A) showed slight random deviations from the additivity rule (dashed line), confirming the ideal behaviour of the PE:PG Langmuir films regardless the PG content. The $\Delta \mathrm{G}_{\text {mix }}$ curves (Fig. $3 \mathrm{~B}$ ) presented negative values for all tested mixtures, confirming their stability (Roche et al. 2006).

\section{$\pi$-A isotherms, physical states and mixing behaviour of PE:CL system}

The CL $\pi$-A isotherm at $37^{\circ} \mathrm{C}$ (Fig. 4) showed the lift-off area at $240 \AA^{2} /$ molecule and the collapse of the film at $\pi=$ $47 \mathrm{mN} / \mathrm{m}$. The $\mathrm{C}_{\mathrm{s}}{ }^{-1}$ max $\approx 94 \mathrm{mN} / \mathrm{m}$ (inset of Fig. 4) indicates the LE physical state of the monolayer (Vitovič et al. 2006). The comparable hydrocarbon chains of PE and CL lead to similar isotherms and $\mathrm{C}_{\mathrm{s}}{ }^{-1}$ curves for their mixed monolayers. The increased molecular area observed upon increasing the CL content is correlated with the larger volume that occupy the four hydrocarbon chains in $\mathrm{CL}$ compared to the volume of two hydrocarbon chains in $\mathrm{PE}$ (Baumgärtner et al. 2007; Boyd et al. 2017).

The mean area per molecule vs. molar fraction curves (Fig. 5A) exhibited slightly positive deviations from the additivity rule (dashed line), corroborating that $\mathrm{PE}: \mathrm{CL}$ system constitutes slightly non-ideal films at $\pi>5 \mathrm{mN} / \mathrm{m}$. The negative $\Delta \mathrm{G}_{\text {mix }}$ values (Fig. $5 \mathrm{~B}$ ) observed for all the mixtures indicate the stability (Roche et al. 2006) of the studied PE:CL mixtures.

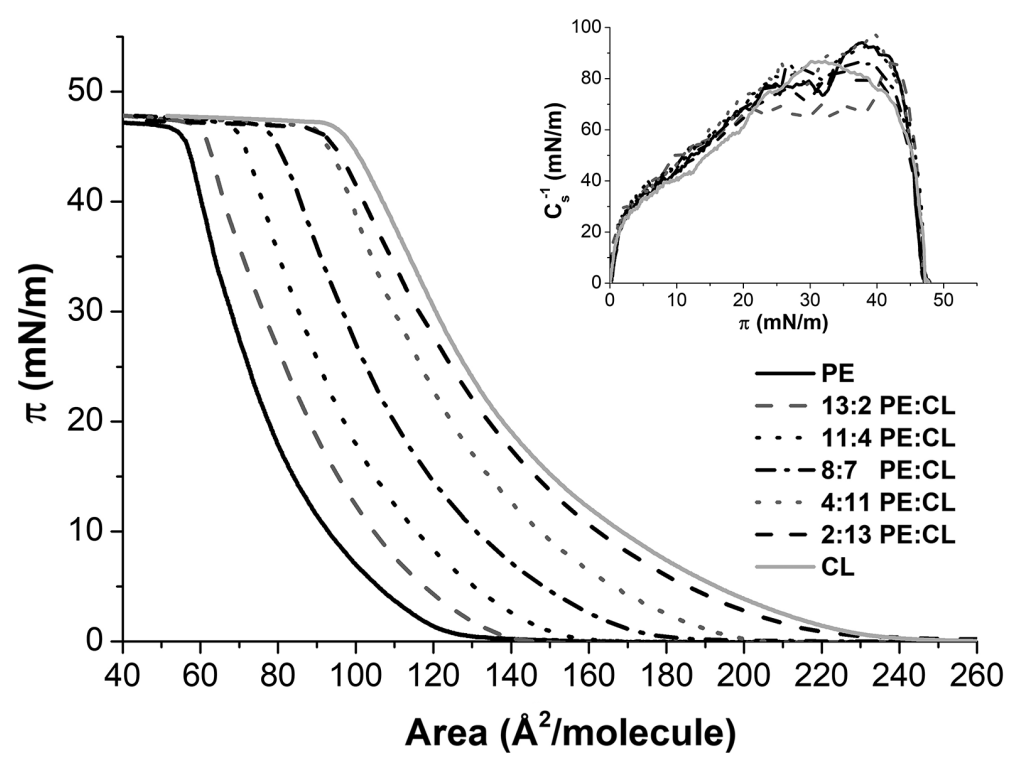

Figure 4. Surface pressure-area $(\pi-A)$ isotherms for phosphatidylethanolamine $(\mathrm{PE})$, cardiolipin (CL) and PE:CL mixtures on PBS subphase at $37^{\circ} \mathrm{C}$. Inset: Inverse of the compressibility modulus $\left(\mathrm{C}_{\mathrm{s}}^{-1}\right)$ vs. surface pressure corresponding to the described $\pi$-A isotherms. 


\section{Discussion}

The current work used a myriad of natural lipid structures that share the same headgroup, but contain acyl chains with different length and degree of unsaturation, for preparing model bacterial membranes. PE:PG and PE:CL mixtures at $37^{\circ} \mathrm{C}$ showed higher lift-off areas (Fig. 2 and 4 ) than those observed at $23^{\circ} \mathrm{C}$ (Hoyo et al. 2019b). On the contrary, the collapse surface pressure was lowered upon the increase of temperature. Higher temperature favours the lipid vibrations and the dissociation of ionisable groups (Krajewska et al. 2013b) - PG and CL headgroups - inducing higher molecular areas. The PE:PG system yielded a higher liftoff area difference $\sim 30 \AA^{2} /$ molecule than PE:CL $\sim 20 \AA^{2} /$ molecule upon the temperature increase, attributed to the stronger interactions observed in the PE:PG system compared to PE:CL at $23^{\circ} \mathrm{C}$ (Hoyo et al. 2019b). Similarly, Suárez-Germà et al. (2011) observed that monolayers of lipids with PE headgroup presented higher lift-off area as the number of unsaturations of the hydrocarbon chains or the temperature was increased, according to observations for DPPG (Krajewska et al. 2013b) and dipalmitoylphosphatidylcholine (Krajewska et al. 2013a). The characteristics of the acyl chains (unsaturation and chains length) contributed to the steric hindrances between individual lipids resulting in a lower packing.

The $\mathrm{C}_{\mathrm{s}}{ }^{-1}$ max for the single lipids and their corresponding mixtures decreased below $100 \mathrm{mN} / \mathrm{m}$, indicating that all studied systems present LE physical state in accordance to the results observed at $23^{\circ} \mathrm{C}$ (Hoyo et al. 2019b), where only PE lipid monolayer reached the liquid condensed (LC) state. The increase of the temperature favours the dissociation of ionisable groups (Krajewska et al. 2013b) and lowers the packing, thus yielding fluid phases. The rigidity of the studied systems at $23^{\circ} \mathrm{C}$ was slightly higher than at $37^{\circ} \mathrm{C}$. The characteristics of the isotherms and the LE state observed for the binary PE:PG and PE:CL systems (Fig. 2 and 4) are in line with previous studies using a natural ternary mixture (Clausell et al. 2004; López-Montero et al. 2008). The presence of unsaturations promoted the formation of fluid phases in our PE:PG and PE:CL systems (inset of Fig. 2 and 4). Such phenomenon was also described (Suárez-Germà et al. 2011) for palmitoyloleoylphosphatidylethanolamine (POPE) and POPG that became less rigid upon increasing the number of unsaturations whereas the saturated dipalmitoylphosphatidylethanolamine reached solid state (S) (HernándezBorrell and Domènech 2017). The PE:PG and PE:CL systems formed almost ideal monolayers at $37^{\circ} \mathrm{C}$ (Fig. $3 \mathrm{~A}$ and $5 \mathrm{~A}$ ). In contrast, the PE:CL system showed non-ideal films at $23^{\circ} \mathrm{C}$, inducing non-favoured mixtures when the amount of $\mathrm{PE}$ or CL was above $20 \%$ and $\pi \geq 30 \mathrm{mN} / \mathrm{m}$ (Hoyo et al. 2019b). This observation is explained by the higher repulsion and vibration between lipids upon increasing the temperature.
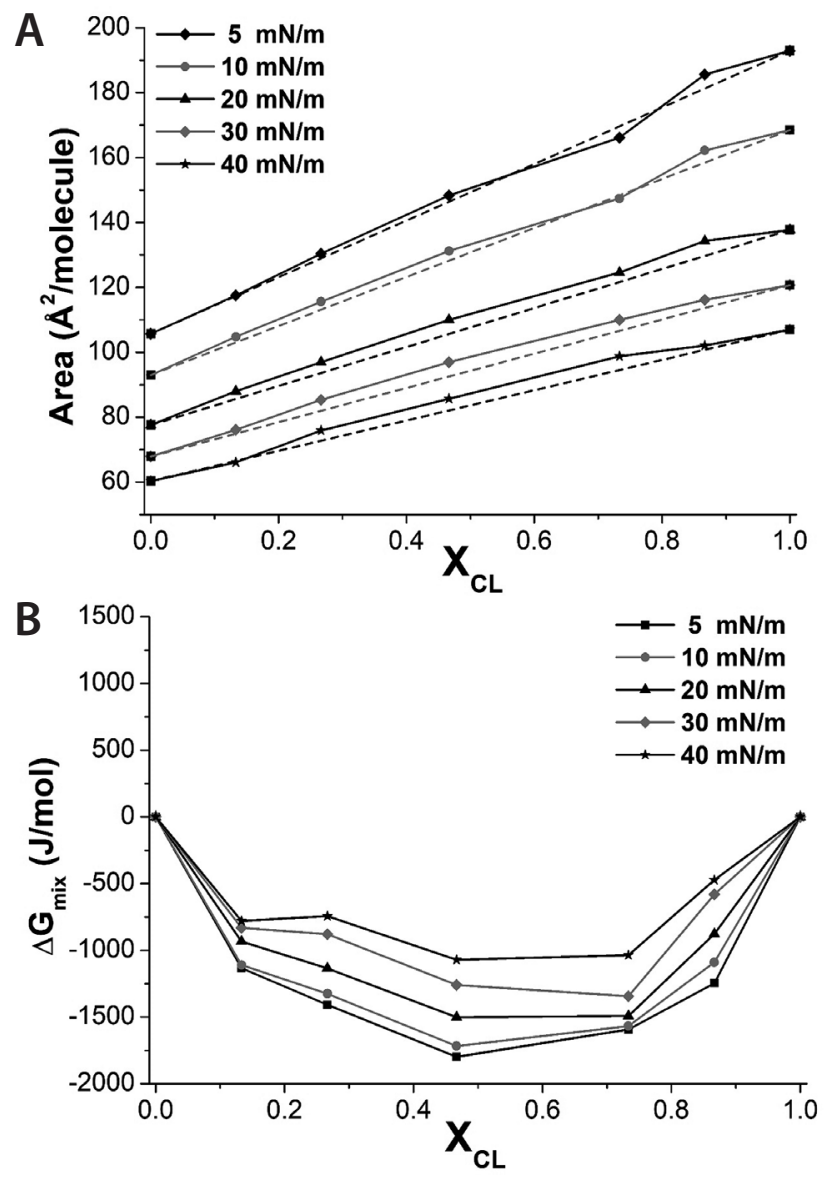

Figure 5. Mean area per molecule vs. molar fraction $\left(\mathrm{X}_{\mathrm{CL}} ; \mathbf{A}\right)$ and mixing energy $\left(\Delta G_{\text {mix }}\right) v s$. molar fraction $(\mathbf{B})$ at several surface pressures for the $\mathrm{PE}: \mathrm{CL}$ system at $37^{\circ} \mathrm{C}$. Discontinuous straight line represents the ideal behaviour for each surface pressure.

The thermodynamic study showed negative $\Delta \mathrm{G}_{\mathrm{mix}}$ values for all studied systems (Fig. 3B and 5B), thus indicating the stability of the mixtures and the absence of phase separation (Gzyl-Malcher et al. 2008) domains for both PE:PG and PE:CL systems, regardless the PE:lipid ratio, contrarily to the $\mathrm{PE}: \mathrm{CL}$ system unstable at $23^{\circ} \mathrm{C}$. The formation of domains was observed for the POPE:CL (Domènech et al. 2006b) and POPE:POPG 3:1 (Seeger et al. 2009; Picas et al. 2010; Suárez-Germà et al. 2011) systems both in LB and supported planar bilayers - widely used for biomimetic membranes construction (Domènech et al. 2006b; Hoyo et al. 2013) below and above the melting temperature. These observations were attributed to the tendency of POPE to form LC phase (Suárez-Germà et al. 2011) and the presence of $\mathrm{Ca}^{2+}$ ions that resulted in stronger interaction with POPG than with POPE (Picas et al. 2010), thus inducing phase separation. Oppositely to the POPE:POPG and POPE:CL systems, the thermodynamic studies of biomimetic membranes with 
a natural myriad of bacterial lipids indicated the absence of phase separation domains at $37^{\circ} \mathrm{C}$ (López-Montero et al. 2008). Nevertheless, the same authors (López-Montero et al. 2008) observed their presence by epifluorescence microscopy, whereas Domènech et al. (2006a) did not detect such domains by atomic force microscopy (AFM), in line with our thermodynamic results (Fig. 3B and Fig. 5B). Most probably, the use of selective fluorescent dyes favors the visualization of such domains in biomimetic membranes (López-Montero et al. 2008), as previously observed in natural bacterial membranes (Mileykovskaya et al. 2001). These apparently contradictory results with some previous studies may be explained by the limitations of the thermodynamic study applied to a multicomponent system. Despite the fact that we have studied binary PE:PG and PE:CL systems at several molar ratios, each lipid named by its headgroup contains several structures, corresponding to different chain length and unsaturation, building a multicomponent system. Therefore the emergence of nanoscale lipid domains could be possible as observed in biological membranes (Jacobson et al. 2007).

The temperature of the bacterial membrane environment is an important parameter, since some of the lipid constituents of these membranes present phase transition close to the physiological human temperature (Silvius 1982). Therefore, the physical state influences both the permeability of the membrane and the interactions of the lipids with other membrane components, altering consequently their function (Barrera et al. 2012). Several mechanisms have been reported by which antibacterial agents target bacteria and alter their membrane properties (Epand et al. 2016). Therefore, the physical state and the fluidity of the bacterial membrane is of high relevance for the development of bactericidal agents. Several bacterial model membranes with different degree of similarity to the real membranes are described in the literature, but most of them are composed by only one or two lipid structures. Despite that some of these studies used unsaturated lipids to enhance the fluidity of the resulting membranes, the effect of the biological myriad of lipid structures was not evaluated, thus the reduction of fluidity was not considered neither the different interaction of the lipid structures with the antibacterial agent. In our work, the fluidity of the model membrane formed at $37^{\circ} \mathrm{C}$ was compared to the fluidity of a membrane formed at $23^{\circ} \mathrm{C}$, concluding the athermalicity of the rigidity and physical state for PE:PG and PE:CL systems at biologically relevant temperatures. These results correlate with previous reports for other lipid systems at LE state (López-Montero et al. 2008) and may explain the ability of E.coli membranes to maintain their functionality across a broad temperature range (Remaut and Fronzes 2014) due to intermolecular hydrogen bonding between lipids and transmembrane proteins allowing the correct protein insertion and function in the membrane (Domènech et al. 2006b). The observed athermalicity sug- gested that the effect of antibacterial agents on model lipid membranes would be similar, regardless room or human physiological temperature.

\section{Conclusions}

E.coli model membranes were prepared using bacterium's natural lipid structures. These biomimetic membranes present almost athermal physical state and rigidity, which may be related to the ability of bacteria to maintain their functions at human physiological temperatures. These observations are of high relevance for the design of novel antimicrobial agents targeting the bacterial membranes. Similar behaviour of the bacterial membrane in the range of 23 to $37^{\circ} \mathrm{C}$ was detected, despite that the phase transition temperature of some lipid structures present in E.coli membranes is close to human physiological temperature. Independently from the different strategies that bacteria adopt to adapt their lipid membrane composition to the temperature of the environment, their bulk membrane behaviour in the studied temperature range was not significantly altered. Novel bactericidal agents targeting the bacterial membrane may be engineered considering the athermalicity of the membrane bulk properties. The simple and reliable bacterial membrane model described in this work may be further used for mechanistic studies in vitro of the interactions between bactericidal agents and bacteria.

Acknowledgements. The research leading to these results has received funding from European Community's Horizon 2020 Framework Program H2020 (H2020-720851 project PROTECT - Pre-commercial lines for production of surface nanostructured antimicrobial and anti-biofilm textiles, medical devices and water treatment membranes).

Conflict of interest. The authors declare no competing financial interest.

Author contributions. The manuscript was written through contributions of all authors. All authors have given approval to the final version of the manuscript.

\section{References}

Barrera FN, Fendos J, Engelman DM (2012): Membrane physical properties influence transmembrane helix formation. Proc. Natl. Acad. Sci. USA 109, 14422-14427 https://doi.org/10.1073/pnas.1212665109

Baumgärtner P, Geiger M, Zieseniss S, Malleier J, Huntington JA, Hochrainer K, Bielek E, Stoeckelhuber M, Lauber K, Scherfeld D, et al. (2007): Phosphatidylethanolamine critically supports internalization of cell-penetrating protein C inhibitor. J. Cell. Biol. 179, 793-804 
https://doi.org/10.1083/jcb.200707165

Boyd KJ, Alder NN, May ER (2017): Buckling under pressure: curvature-based lipid segregation and stability modulation in cardiolipin-containing bilayers. Langmuir 33, 6937-6946 https://doi.org/10.1021/acs.langmuir.7b01185

Clausell A, Busquets MA, Pujol M, Alsina A, Cajal Y (2004): Polymyxin B-lipid interactions in Langmuir-Blodgett monolayers of Escherichia coli lipids: A thermodynamic and atomic force microscopy study. Biopolymers 75, 480-490 https://doi.org/10.1002/bip.20165

Clausell A, Garcia-Subirats M, Pujol M, Busquets MA, Rabanal F, Cajal Y (2007): Gram-negative outer and inner membrane models: Insertion of cyclic cationic lipopeptides. J. Phys. Chem. B 111, 551-563 https://doi.org/10.1021/jp064757+

Doménech Ò, Merino-Montero S, Montero MT, Hernández-Borrell J (2006a): Surface planar bilayers of phospholipids used in protein membrane reconstitution: an atomic force microscopy study. Colloids Surfaces B Biointerfaces 47, 102-106 https://doi.org/10.1016/j.colsurfb.2005.11.025

Domènech Ò, Sanz F, Montero MT, Hernández-Borrell J (2006b): Thermodynamic and structural study of the main phospholipid components comprising the mitochondrial inner membrane. Biochim. Biophys. Acta 1758, 213-221 https://doi.org/10.1016/j.bbamem.2006.02.008

Epand RM, Walker C, Epand RF, Magarvey NA (2016): Molecular mechanisms of membrane targeting antibiotics. Biochim. Biophys. Acta 1858, 980-987

https://doi.org/10.1016/j.bbamem.2015.10.018

Fernandes MM, Ivanova K, Hoyo J, Pérez-Rafael S, Francesko A, Tzanov T (2017): Nanotransformation of vancomycin overcomes the intrinsic resistance of Gram-negative bacteria. ACS Appl. Mater. Interfaces 9, 15022-15030 https://doi.org/10.1021/acsami.7b00217

Ferreres G, Bassegoda A, Hoyo J, Torrent-Burgués J, Tzanov T (2018): Metal-enzyme nanoaggregates eradicate both GramPositive and Gram-Negative bacteria and their biofilms. ACS Appl. Mater. Interfaces 10, 40434-40442 https://doi.org/10.1021/acsami.8b14949

Gidalevitz D, Ishitsuka Y, Muresan AS, Konovalov O, Waring AJ, Lehrer RI, Lee KYC (2003): Interaction of antimicrobial peptide protegrin with biomembranes. Proc. Natl. Acad. Sci. USA 100, 6302-6307

https://doi.org/10.1073/pnas.0934731100

Gzyl-Malcher B, Filek M, Makyła K, Paluch M (2008): Differences in surface behaviour of galactolipoids originating from different kind of wheat tissue cultivated in vitro. Chem. Phys. Lipids 155, 24-30 https://doi.org/10.1016/j.chemphyslip.2008.06.004

Hernández-Borrell J, Domènech Ò (2017): Critical temperature of 1-palmitoyl-2-oleoyl-sn-glycero-3-phosphoethanolamine monolayers and its possible biological relevance. J. Phys. Chem. B 121, 6882-6889 https://doi.org/10.1021/acs.jpcb.7b04021

Hoyo J, Guaus E, Torrent-Burgués J, Sanz F (2012): Electrochemical behaviour of mixed LB films of ubiquinone - DPPC. J. Electroanal. Chem. 669, 6-13 https://doi.org/10.1016/j.jelechem.2012.01.020
Hoyo J, Guaus E, Oncins G, Torrent-Burgués J, Sanz F (2013): Incorporation of ubiquinone in supported lipid bilayers on ITO. J. Phys. Chem. B 117, 7498-7506 https://doi.org/10.1021/jp4004517

Hoyo J, Guaus E, Torrent-Burgués J, Sanz F (2015): Biomimetic monolayer films of digalactosyldiacylglycerol incorporating plastoquinone. Biochim. Biophys. Acta 1848, 1341-1351 https://doi.org/10.1016/j.bbamem.2015.03.003

Hoyo J, Guaus E, Torrent-Burgués J (2016a): Monogalactosyldiacylglycerol and digalactosyldiacylglycerol role, physical states, applications and biomimetic monolayer films. Eur. Phys. J. E 39, 1-11 https://doi.org/10.1140/epje/i2016-16039-0

Hoyo J, Guaus E, Torrent-Burgués J (2016b): Influence of membrane galactolipids and surface pressure on plastoquinone behaviour. Bioelectrochemistry 111, 123-130 https://doi.org/10.1016/j.bioelechem.2016.06.002

Hoyo J, Ivanova K, Guaus E, Tzanov T (2019a): Multifunctional ZnO NPs-chitosan-gallic acid hybrid nanocoating to overcome contact lenses associated conditions and discomfort. J. Colloid. Interface Sci. 543, 114-121 https://doi.org/10.1016/j.jcis.2019.02.043

Hoyo J, Torrent-Burgués J, Tzanov T (2019b): Physical states and thermodynamic properties of model gram-negative bacterial inner membranes. Chem. Phys. Lipids 218, 57-64 https://doi.org/10.1016/j.chemphyslip.2018.12.003

Ivanova A, Ivanova K, Hoyo J, Heinze T, Sanchez-Gomez S, Tzanov T (2018): Layer-by-layer decorated nanoparticles with tunable antibacterial and antibiofilm properties against both Gram-Positive and Gram-Negative bacteria. ACS Appl. Mater. Interfaces 10, 3314-3323 https://doi.org/10.1021/acsami.7b16508

Ivanova K, Ramon E, Hoyo J, Tzanov T (2017): Innovative approaches for controlling clinically relevant biofilms: current trends and future prospects. Curr. Top. Med. Chem. 17, 1889-1914 https://doi.org/10.2174/1568026617666170105143315

Jacobson K, Mouritsen OG, Anderson RGW (2007): Lipid rafts: at a crossroad between cell biology and physics. Nat. Cell. Biol. 9, 7-14 https://doi.org/10.1038/ncb0107-7

Krajewska B, Wydro P, Kyzioł A (2013a): Chitosan as a subphase disturbant of membrane lipid monolayers. The effect of temperature at varying pH: II. DPPC and cholesterol. Colloids Surfaces A Physicochem. Eng. Asp. 434, 359-364 https://doi.org/10.1016/j.colsurfa.2013.03.018

Krajewska B, Wydro P, Kyzioł A (2013b): Chitosan as a subphase disturbant of membrane lipid monolayers. The effect of temperature at varying pH: I. DPPG. Colloids Surfaces A Physicochem. Eng. Asp. 434, 349-358 https://doi.org/10.1016/j.colsurfa.2013.03.015

Larsson G, Törnkvist M (1996): Rapid sampling, cell inactivation and evaluation of low extracellular glucose concentrations during fed-batch cultivation. J. Biotechnol. 49, 69-82 https://doi.org/10.1016/0168-1656(96)01534-9

López-Montero I, Arriaga LR, Monroy F, Rivas G, Tarazona P, Vélez M (2008): High fluidity and soft elasticity of the inner membrane of escherichia coli revealed by the surface rheology of model langmuir monolayers. Langmuir 24, 4065-4076 https://doi.org/10.1021/la703350s 
López-Montero I, Arriaga LR, Rivas G, Vélez M, Monroy F (2010): Lipid domains and mechanical plasticity of Escherichia coli lipid monolayers. Chem. Phys. Lipids 163, 56-63 https://doi.org/10.1016/j.chemphyslip.2009.10.002

Michel JP, Wang Y, Dé E, Fontaine P, Goldmann M, Rosilio V (2015): Charge and aggregation pattern govern the interaction of plasticins with LPS monolayers mimicking the external leaflet of the outer membrane of Gram-negative bacteria. Biochim. Biophys. Acta 1848, 2967-2979 https://doi.org/10.1016/j.bbamem.2015.09.005

Michel JP, Wang Y, Kiesel I, Gerelli Y, Rosilio V (2017): Disruption of asymmetric lipid bilayer models mimicking the outer membrane of gram-negative bacteria by an active plasticin. Langmuir 33, 11028-11039 https://doi.org/10.1021/acs.langmuir.7b02864

Mileykovskaya E, Dowhan W, Birke RL, Zheng D, Lutterodt L, Haines TH (2001): Cardiolipin binds nonyl acridine orange by aggregating the dye at exposed hydrophobic domains on bilayer surfaces. FEBS Lett. 507, 187-190 https://doi.org/10.1016/S0014-5793(01)02948-9

Nichols-Smith S, Teh S-YY, Kuhl TL (2004): Thermodynamic and mechanical properties of model mitochondrial membranes. Biochim. Biophys. Acta 1663, 82-88 https://doi.org/10.1016/j.bbamem.2004.02.002

Picas L, Suárez-Germà C, Teresa Montero M, Hernández-Borrell J (2010): Force spectroscopy study of langmuir-blodgett asymmetric bilayers of phosphatidylethanolamine and phosphatidylglycerol. J. Phys. Chem. B 114, 3543-3549 https://doi.org/10.1021/jp910882e

Remaut H, Fronzes R (2014): Bacterial Membranes, Structural and Molecular Biology. Caister Academic Press
Roche Y, Peretti P, Bernard S (2006): Influence of the chain length of ubiquinones on their interaction with DPPC in mixed monolayers. Biochim. Biophys. Acta 1758, 468-478 https://doi.org/10.1016/j.bbamem.2006.03.015

Seeger H, Marino G, Alessandrini A, Facci P (2009): Effect of physical parameters on the main phase transition of supported lipid bilayers. Biophys. J. 97, 1067-1076 https://doi.org/10.1016/j.bpj.2009.03.068

Shokri A, Larsson G (2004): Characterisation of the Escherichia coli membrane structure and function during fedbatch cultivation. Microb. Cell. Fact. 3, 9 https://doi.org/10.1186/1475-2859-3-9

Silvius JR (1982): Thermotropic Phase Transitions of Pure Lipids in Model Membranes and Their Modifications by Membrane Proteins. John Wiley Sons, Inc

Suárez-Germà C, Montero MT, Ignés-Mullol J, Hernández-Borrell J, Domènech Ò (2011): Acyl chain differences in phosphatidylethanolamine determine domain formation and LacY distribution in biomimetic model membranes. J. Phys. Chem. B 115, 12778-12784 https://doi.org/10.1021/jp206369k

Vitovič P, Nikolelis DP, Hianik T (2006): Study of calix[4]resorcinarene-dopamine complexation in mixed phospholipid monolayers formed at the air-water interface. Biochim. Biophys. Acta 1758, 1852-1861 https://doi.org/10.1016/j.bbamem.2006.08.011

Yeagle PL (2016): The Membranes of Cells. Academic PressElsevier, San Diego, California

Received: October 8, 2019

Final version accepted: December 17, 2019 